NASA Technical Memorandum 106671

AIAA-94-2694

\title{
Effects of a Forward-Swept Front Rotor on the Flowfield of a Counterrotation Propeller
}

M. Nallasamy

NYMA, Inc.

Engineering Services Division

Brook Park, Ohio

and

Gary G. Podboy

National Aeronautics and Space Administration

Lewis Research Center

Cleveland, Ohio

Prepared for the

30th Joint Propulsion Conference

cosponsored by the AIAA, ASME, SAE, and ASEE

Indianapolis, Indiana, June 27-29, 1994

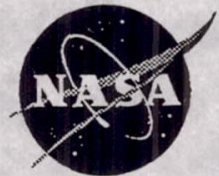

National Aeronautics and Space Administration 


\title{
Effects of a Forward-swept Front Rotor on the Flowfield of a Counterrotation Propeller
}

\author{
M. Nallasamy \\ NYMA, Inc., Brook Park, Ohio 44142 \\ and \\ Gary G. Podboy \\ NASA Lewis Research Center, Cleveland, Ohio 44135
}

\begin{abstract}
The effects of a forward-swept front rotor on the flowfield of a counterrotation model propeller at takeoff conditions at zero degree angle of attack-are studied by solving the unsteady three-dimensional Euler equations. The configuration considered is an uneven blade count counterrotation model with twelve forward-swept blades on the fore rotor and ten aft-swept blades on the aft rotor. The flowfield is compared with that of a reference aft-swept counterrotation geometry and Laser Doppler Velocimeter (LDV) measurements. At the operating conditions considered, the forward- swept blade experiences a higher tip loading and produces a stronger tip vortex compared to the aft-swept blade, consistent with the LDV and acoustic measurements. Neither the solution nor the LDV data indicated the formation of a leading edge vortex. The predicted radial distribution of the circumferentially averaged axial velocity at the measurement station agreed very closely with LDV data, while crossflow velocities showed poor agreement. The discrepancy between prediction and LDV data of tangential and radial velocities is due in part to the insufficient mesh resolution in the region between the rotors and in the tip region to track the tip vortex. The vortex is diffused by the time it arrives at the measurement station. The uneven blade count configuration requires the solution to be carried out for six blade passages of the fore rotor and five passages of the aft rotor, thus making grid refinement prohibitive.
\end{abstract}

\section{Introduction}

Advanced counterrotation propellers have been

- This paper is declared a work of the U.S. Government and is not subject to copyright protection in the United States shown to offer fuel savings of about ten percent over the single rotation propellers. The improved fuel efficiency stems from the recovery of the swirl loss of the front rotor by the rear rotor. However, the interaction of the flowfields of the rotors of the counterrotation propellers generate more noise than the single rotation propellers. Further improvements in fuel efficiency and noise reduction may result only from a better understanding of the flow features of the counterrotation propellers. This understanding may lead to improvements in the design methodologies for future counterrotation configurations.

One of the ways of reducing the interaction noise of the counterrotation propellers is thought to be the replacement of the conventional aft-swept front rotor by a forward-swept rotor. On a forward-swept blade, the leading edge vortex, if one exists; would move inboard away from the tip vortex resulting in two distinct vortices. This would result in a smaller blade wake velocity defect in the tip region and a weaker tip vortex. With the aft-sweep, the leading edge and tip vortices merge to produce a stronger tip vortex and a higher velocity defect in the tip region. A forward-swept rotor arrangement also results in a larger distance between the tips of the front and aft blades, allowing for more decay of the tip vortex and the blade wake in the tip region before impinging on the rear rotor blade. It is thus expected that a counterrotation configuration with a forward-swept front rotor would result in a low interaction noise.

The effect of forward-sweep was tested by Simonich et. al. ${ }^{1}$ by installing a stationary vane upstream of a rotating propfan. They compared the flowfields of forward-swept and aft-swept vanes, using hot-wire and flow visualization data. Acoustic measurements were used to determine the effect of 
wakes on the interaction noise. As expected, the forward-sweep produced a wake with a small velocity defect in the tip region and less interaction noise compared to the aft-sweep.

The flowfield of forward-swept rotating blades was studied by Lavrich et. al $^{2}$ They employed aftswept blades in a forward- swept configuration by staggering the blades nearly 180 degrees, reversing the leading and trailing edges of the blade. In this arrangement the maximum leading edge sweep was 20 degrees at 75 percent blade radius. Hot-wire measurements, flow visualization, and total pressure surveys were made to document the flow. They found that the forward-swept arrangement produced, as in the forward-swept vane experiment, a more uniform wake flow downstream of the blade tips compared to that of the aft-swept blade. However, further inboard, a massive flow separation from the suction surface of the forward-swept blades resulted in a wide inboard wake downstream of each front rotor blade. It was estimated that such a wide inboard wake would result in more interaction noise. The authors surmised that increasing the leading edge sweep would allow the formation of a leading edge vortex and prevent the massive flow separation.

A counterrotation propeller model with a forward-swept front rotor was recently tested in the $9^{\prime} \times 15$ ' wind tunnel at NASA Lewis to examine the effects of forward-sweep on the flowfield and acoustics. The forward-swept rotor had 30 degrees of leading edge sweep over the outer 40 percent of the blade span. Laser Doppler Velocimetry (LDV) was used to measure the rotor wake characteristics of the forward-swept rotor (Fig. 1) and a reference aft-swept rotor (Fig. 2). The forward-swept rotor test matrix, however, was limited to low power due to problems with the aeromechanical design of the forward-swept blade. The blade experienced significant tip twist under load and showed a tendency to go into incipient flutter at high speeds. LDV measurements ${ }^{3}$ and acoustic measurements ${ }^{4}$ were made at rotational speeds of about 75 percent of the design speed of the forward-swept blade and data were compared with the aft-swept reference counterrotation configuration. The flow measurements showed that contrary to the expectations the forward-swept blade produced a stronger tip vortex compared to the aft-swept blade. The data did not indicate any flow separation. The acoustic measurements showed that the fundamental rotor-alone tones for the forward-swept model were higher than that of the reference aft-swept model. The interaction tones were also higher, up to $8 \mathrm{~dB}$. The disappointing performance of the forward-swept model configuration was attributed to its aeromechanical design problem.

In the present article the flowfield of the above counterrotation propeller model with a forwardswept front rotor is studied by solving the unsteady Euler equations and compared with that of the reference aft-swept model. The tip vortex, blade loading, velocity distribution, and axial vorticity are examined. Comparisons are also made with the LDV measurements.

Numerical Solution of Unsteady, ThreeDimensional Euler Equations

The unsteady three-dimensional Euler equations governing the inviscid flow through a counterrotation propeller with uneven blade count are solved by employing a solution procedure developed by Janus and Whitfield ${ }^{5}$. In this procedure the Euler equations in conservative differential form are transformed from a Cartesian reference frame to a body fitted curvilinear reference frame. The transformed equations are discretized employing a finite volume technique. An approximate Riemann solver is used for block interface flux definitions and a lower-upper (LU) implicit numerical scheme is used to solve the discretized equations.

The algorithm developed in ${ }^{5}$ uses a selected similarity mapped multiblock method to limit the computer core memory requirements. Circumferential and axial partitioning of the computational domain are usually employed. Axial partitioning is also referred to as a blade row. For all blocks within a blade row, the axial, radial, and circumferential grid indices ( $\mathrm{ni}, \mathrm{nj}$, and nk respectively) must remain constant. The radial index, nj, must remain constant between blade rows. Although ni and nk may vary between blade rows, the blade row circumferential cell count must match.

\section{Flow Configuration and Computational Grid}

The counterrotation propeller model considered in the study is an uneven blade count configuration, F39/A31 with a forward-swept front rotor (Fig. 1). There were twelve blades in the front row and ten blades in the rear row. The flowfield of an aft-swept reference counterrotation configuration, F31/A31 (Fig. 2) was also solved for compar- 
ison. The front rotor of this model had twelve aftswept blades. Both configurations had the same aft rotor (A31) with ten aft-swept blades. The forward rotor diameter was 26.0 inches while that of the aft was 24.8 inches. The axial spacing between the pitch change axes of the two rotors was 7.22 inches or 27.6 percent of the front rotor diameter. The forward row rotates clockwise and the aft row rotates counterclockwise as seen from the front. Because of the uneven blade count, the solution algorithm requires that six blade passages of the front rotor and five blade passages of the rear rotor be solved. It also complicates the solution restart procedure in that the restart files cannot be written at will, but only at every $1 / 2$ revolution. These factors restrict the number of grid points that can be specified to represent each flow passage while keeping the computational times within practical limits.

The computational domain is divided into two blade rows. In the front row, each blade passage is represented as one block giving six blocks of grid. Each block had $79 \times 37 \times 16$ grid points. The five blade passages of the aft row were represented by five blocks, each having $73 \times 37 \times 19$ grid points. Each block was H-type grid in all directions. In the circumferential direction there were 91 grid points for the six blade passages of the front rotor or for the five blade passages of the aft rotor. Each blade surface is represented by $36 \times 24$ (axial by radial) grid points with higher resolution near the leading and trailing edges, the hub, and the tip for more accurate calculation of blade surface pressures. The dynamic blade coordinates, accounting for blade deflection under aerodynamic loading, were used to generate the grid. The distribution of grid points on and near the blades is shown in Fig. 3 for forwardswept configuration and in Fig. 4 for aft-swept reference geometry. All computations reported here were done on Cray Y-MP at NASA Lewis.

\section{Results and Discussion}

The forward-swept model was tested in the wind tunnel with the blade setting angles of 35 degrees on the forward rotor and 38.2 degrees on the aft rotor, at 75 percent of the blade tip radii. The advance ratios of the forward and aft rotors were 1.127 and 1.160 respectively. The two rotors were operated at about $100 \mathrm{rpm}$ difference to avoid the higher test rig vibration experienced with nearly equal speeds. Further details of the test, the LDV measurement system, and the LDV data may be found in ${ }^{4}$. The same blade angles as that of the test were used in the present computations. The advance ratio of both the forward and aft rotors was set to 1.127 (to avoid complex data manipulation and book keeping in generating and using restart files) and the free stream Mach number was 0.2. The computations of the reference aft-swept geometry were done matching the blade setting angles and the advance ratio with that of the forward-swept. All the computations were done for zero degree angle of attack.

From an impulse start, the unsteady Euler simulation was run for four complete revolutions of the blade to obtain a reasonably accurate solution. The solution obtained is analyzed and presented here. Figure $5 \mathrm{a}$ shows the unsteady blade power coefficients of the front and rear rotors of the forward-swept counterrotation geometry while Fig. $5 \mathrm{~b}$ shows that of the aft-swept configuration. In either case the magnitude of the fluctuation of the power coefficient of the front rotor is smaller than that of the rear rotor as would be expected from the wake interaction. For the forward blade, ten distinct cycles superpased on a low frequency transient oscillation are observed due to the passage of ten aft blades in half a revolution. Similarly, the aft blade experiences twelve cycles due to the passage of twelve front blades in that half revolution.

The variation of the total power coefficient during the four revolutions is shown in Fig. 6a for the forward-swept configuration and in Fig. $6 \mathrm{~b}$ for the reference geometry. The figures show that the solutions have reached the asymptotic steady state. The computed power coefficient of the forwardswept fore rotor was underpredicted by 16.7 percent while that of the aft rotor was overpredicted by 14 percent.

Figure 7 shows the blade loading distribution along the span for the reference (aft-swept) and forward-swept geometries. It is seen that the forward-swept blade design results in a higher tip loading and eventually results in a stronger tip vortex, contrary to the expectations. Similar results were observed in the experiments ${ }^{3,4}$ and it was concluded that the excessive blade (tip) twist under load was responsible. The chordwise loading distribution is shown at three radial stations, $0.18,0.53$, and 0.81 in Fig. 8. It is seen that, for the forwardswept blade, the leading edge region is highly loaded throughout the span. Also, the trailing edge region shows a small negative loading. The high loading in the leading edge region contributes to the tip loading observed in Fig. 8. A more uniform and re- 
duced loading in the tip region should be produced for the intended application.

On a forward-swept blade, the leading edge vortex, if one exists, would move away from the tip resulting in a weak tip vortex. The blade surface static pressure contours for the two configurations are shown in Fig. 9. The contours on the suction surface do not indicate the formation of a leading edge vortex for the current operating conditions. (A region with closed contours would distinguish the vortex from a low pressure region produced by the flow expansion at the leading edge due to high incidence ${ }^{6}$ ). No flow separation is evident from the contours. The LDV measurements ${ }^{4}$ showed neither the existence of a leading edge vortex nor a flow separation. No leading edge vortex or separation appears on the reference blade also.

Figure 10 shows the axial velocity $(u)$ contours and crossflow vectors (vector sum of crossflow velocities, $v$ and w) just downstream (next grid line) off trailing edge. The view in this figure and succeeding similar figures is from behind the plane plotted, looking upstream. One quadrant of a complete rotor flowfield is illustrated. Formation of tip vortices in both the forward-swept in Fig. 10(a) and the reference aft-swept geometry in Fig. 10 (b) is seen from the clockwise swirl of the crossflow velocity vectors downstream of the blade tips and from the rapid changes in axial velocity in this region. It can be observed that the tip vortex behind the forward-swept blade is stronger and larger in size compared to that behind the aft-swept blade. This is the result of a higher tip loading of the forwardswept blade.

The axial vorticity contours at the same plane downstream of the trailing edge are shown in Fig. 11 for the two configurations. This figure reinforces the statement made above that the forward- swept blade produces a stronger and larger tip vortex for the operating conditions and blade setting angles considered here. The present operating conditions fail to produce a leading edge vortex as noted above.

Radial distributions of circumferentially averaged axial, tangential and radial velocities measured using LDV at an axial station 1.79 inch downstream of the pitch change axis of the forward-swept rotor are shown in Fig. 12. Also shown are the velocities computed from the present Euler simulation, labeled 'CFD'. The predicted flowfield velocities are interpolated along the grid lines to the axial loca- tions of the LDV data. Then they are circumferentially averaged for plots in this figure. The LDV axial velocity profile shows very close agreement with that of CFD. The velocity peak in the tip region is clearly indicated by the prediction. However, the location of that peak occurs more inboard from the blade tip in the prediction as compared to the LDV measurements. This is due to the fast diffusion of the computed vortex as such and insufficient grid resolution to track the vortex accurately. LDV measurements show a tightly wound strong vortex (see below, Fig. 14) resulting in a sharp peak. But the predicted peak velocity is in very good agreement with that of the LDV data. The predicted tangential velocity profile shows a trend similar to that of the LDV measurement, although the values are overpredicted. The absence of a well-defined local peak in the tip region in the prediction is again in part due to the insufficient grid resolution and diffusion of vortex when it reaches the measurement location. The radial velocity is severely underpredicted and the profile predicted shows deviation from the LDV measurements along the entire span where measurements are available. The reasons for this are not clear.

Similar comparisons of the predictions with the LDV data for the aft-swept reference geometry are shown in Fig. 13. It should be noted that while the prediction had a blade setting angle of 35 degrees, the measurements were taken with a blade angle of 38 degrees. Also, note that the measurement is at an axial station 2.42 inches downstream of the pitch change axis of the aft-swept blade. The predicted results do show that the flowfield behind the aftswept blade is characterized by the absence of the peak in axial and tangential velocity components in the tip region observed with the forward-swept blade. The agreement of the predicted axial and tangential velocities with LDV data may be considered reasonable. However, the predicted radial velocities are small and completely different from the LDV data. Such a difference is inexplicable. But it is interesting to note that the measured radial velocities are nearly the same for the forward-swept and aft-swept configurations, while they are significantly different in the predictions.

Figure 14 shows the predicted and measured axial velocity contours at the measurement station downstream of the forward-swept rotor. First of all, the maximum and minimum velocities predicted are quite different from the measurements due to 
insufficient grid resolution in the region. However, the essential characteristics of the flowfield such as the blade wake and tip vortex region are reasonably well represented by the prediction. The predicted axial vorticity contours shown in Fig. 15 again show only a qualitative agreement with the measurements. While the measurements show a tightly wound strong tip vortex, the predictions indicate a highly diffused weak vortex region. For an aft-swept configuration with 8 blades each on the front and rear rotors operating at cruise conditions, Miller and Podboy ${ }^{7}$ obtained solutions using the computational procedure developed by Adamczyk ${ }^{8}$. The even blade count and the steady solution procedure requires that only one blade passage in each rotor be solved. They found that a minimum of 40 points per chord line were required to capture the tip vortex and more than 40 points were needed to resolve the passage shock. (They used $205 \times 61 \times 41$ grid points to represent one blade passage in the front and rear rows). Such a grid refinement is not feasible with the present uneven blade count configuration and unsteady solution method, since six blade passages of the front rotor and five blade passages of the rear rotor are solved.

\section{Concluding Remarks}

The effects of a forward-swept front rotor on the flowfield of a counterrotation propeller were studied employing the three-dimensional Euler simulation. The results were compared with that of the reference aft-swept configuration and the LDV measurements. The predictions clearly show a higher tip loading and the resulting stronger tip vortex trailing off the forward-swept blade compared to that of an aft-swept blade which is in agreement with observation from the LDV data. The predicted axial velocities showed reasonable agreement with LDV data while tangential and radial velocities showed poor agreement. The tip vortex computed is highly diffused and weak due to insufficient grid resolution to track the vortex accurately. Better agreement with data may be expected with grid refinement, but computer resource requirements become prohibitive due to uneven blade count configuration.

\section{Acknowledgements}

Mr. D. Huff's efforts in making available the correct blade coordinates are greatly appreciated. The authors thank Dr. R. Srivatsava for providing the deflected blade coordinates used in the study. Thanks are also due to Dr. O. Yamamoto for generating the grids for the two configurations and many helpful discussions.

\section{References}

1. Simonich, J., McCormic, D., and Haas, R., "The Role of Leading Edge Vortex Flows in Propfan Interaction Noise" AIAA Paper 903977, Oct. 1990.

2. Lavrich, P., Simonich, J., McCormic, D., and Parzych, D., "An Assessment of Wake Structure Behind Forward-swept and Aft- swept Propfans at High Loading", DGLR/AIAA paper 92-02-154, May 1992.

3. Podboy, G.G., and Krupar, M.J., "Laser Velocimeter Measurements of the Flow Field Generated by a Forward-swept Propfan During Flutter", AIAA Paper 93-2919, July 1993.

4. Woodward, R.P., Hall, D.G., Podboy, G.G., and Jeracki, R.J., "Takeoff/Approach Noise for a Model Counterrotation Propeller with a Forward-swept Upstream Rotor", AIAA paper 93-0596, Jan. 1993.

5. Janus, J.M., and Whitfield, D.L., "A Simple Time Accurate Turbomachinery Algorithm with Numerical solution of Uneven Blade Count Configuration", AIAA Paper 89-0206, Jan. 1989.

6. Nallasamy, M. and Groeneweg, J.F., "Unsteady Blade Pressures on a Large-Scale Advanced Propeller: Prediction and Data", Journal of Propulsion and Power, Vol. 7, no. 6, pp. 866872, 1991.

7. Miller, C.J., and Podboy, G.G., "Euler Analysis Comparison with LDV Data for an Advanced Counter-Rotation Propfan at Cruise", AIAA Paper 90-0438.

8. Adamczyk, J.J., "Model Equation for Simulating Flows in Multistage Turbomachinery", ASME Paper 85-GT-226, Nov. 1984. (Also, NASA TM-86869). 


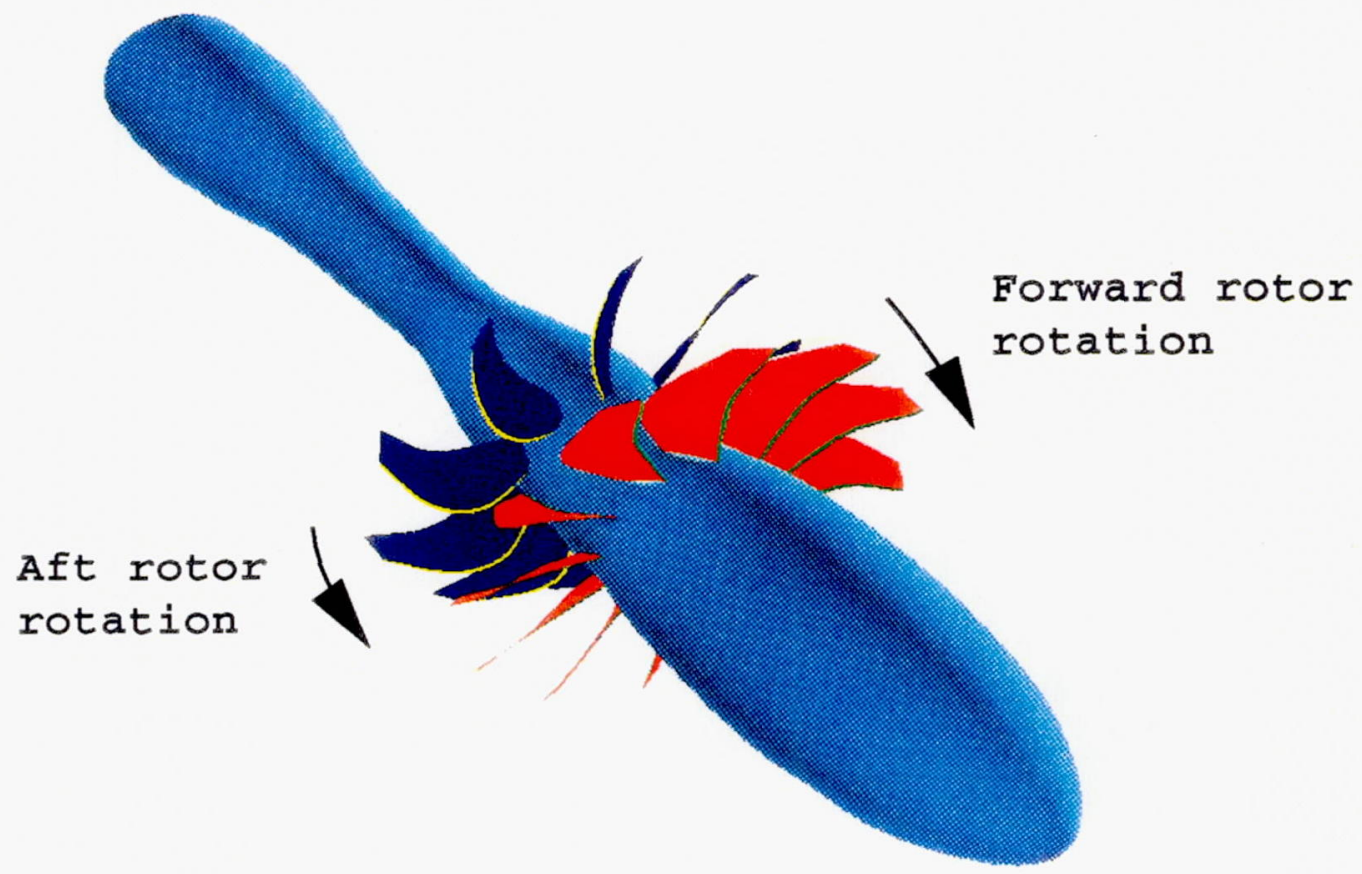

Fig.1 F39/A31 Counterrotation propeller with forward-swept front rotor.

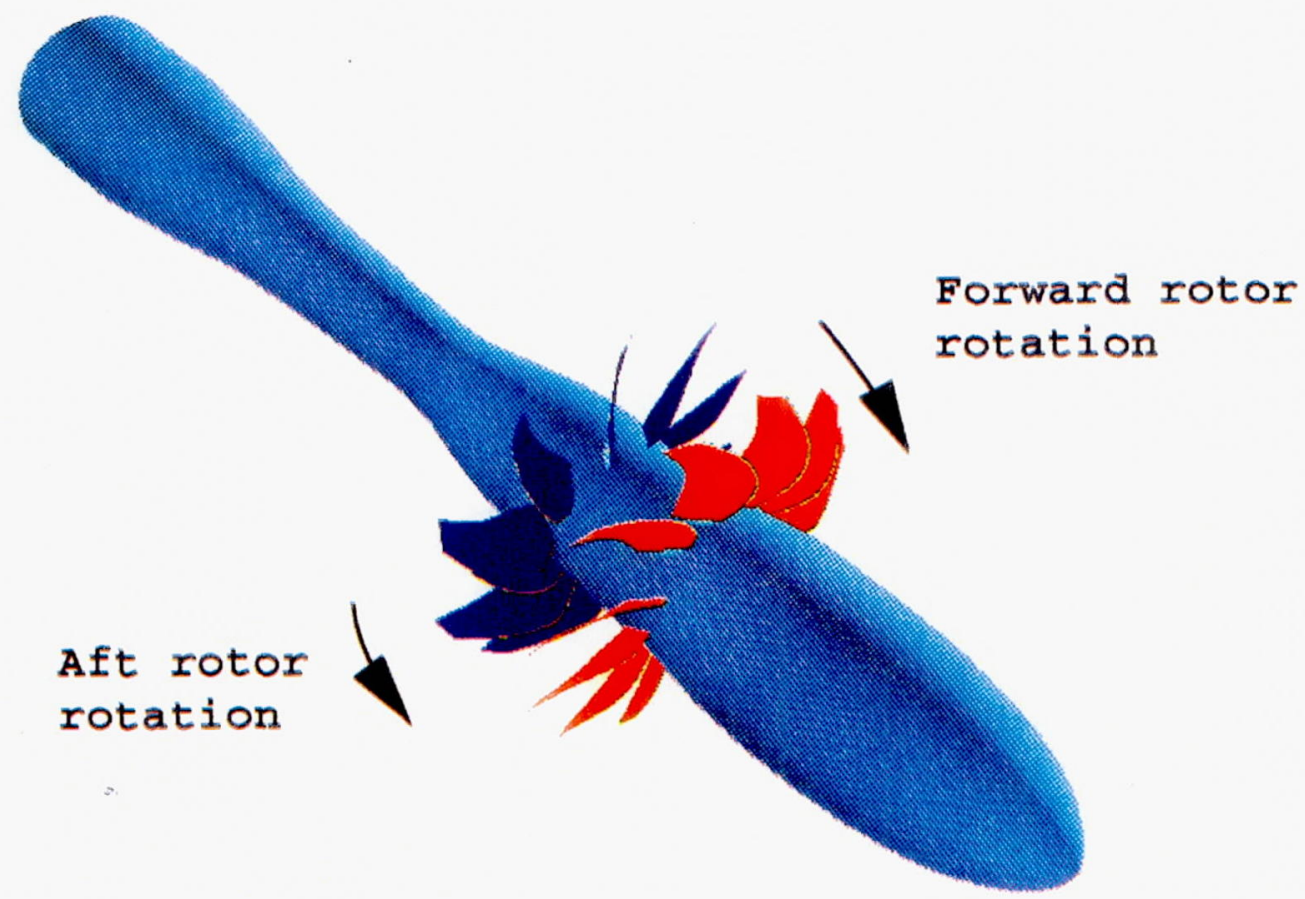

Fig.2 F31/A31 Reference Counterrotation (aft-swept) propeller geometry. 


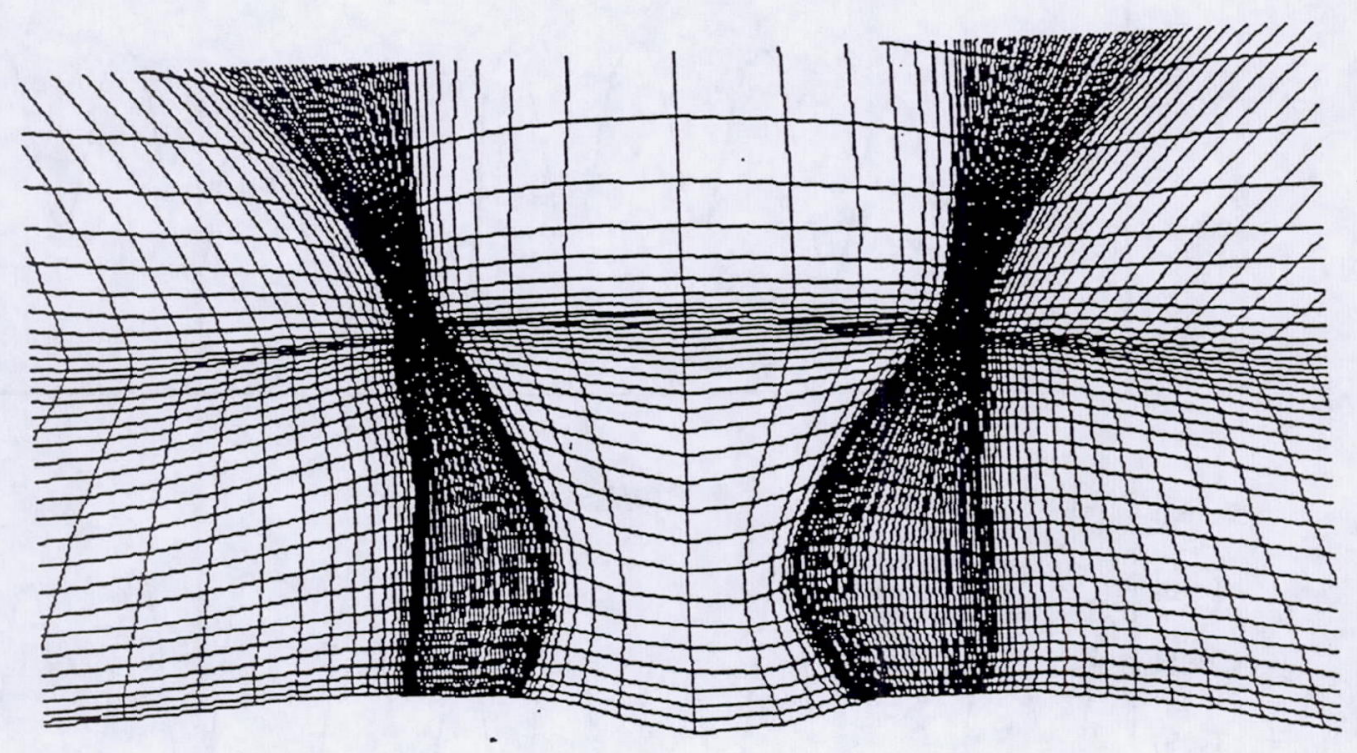

Fig. 3 Distribution of points on and near the F39/A31 blades

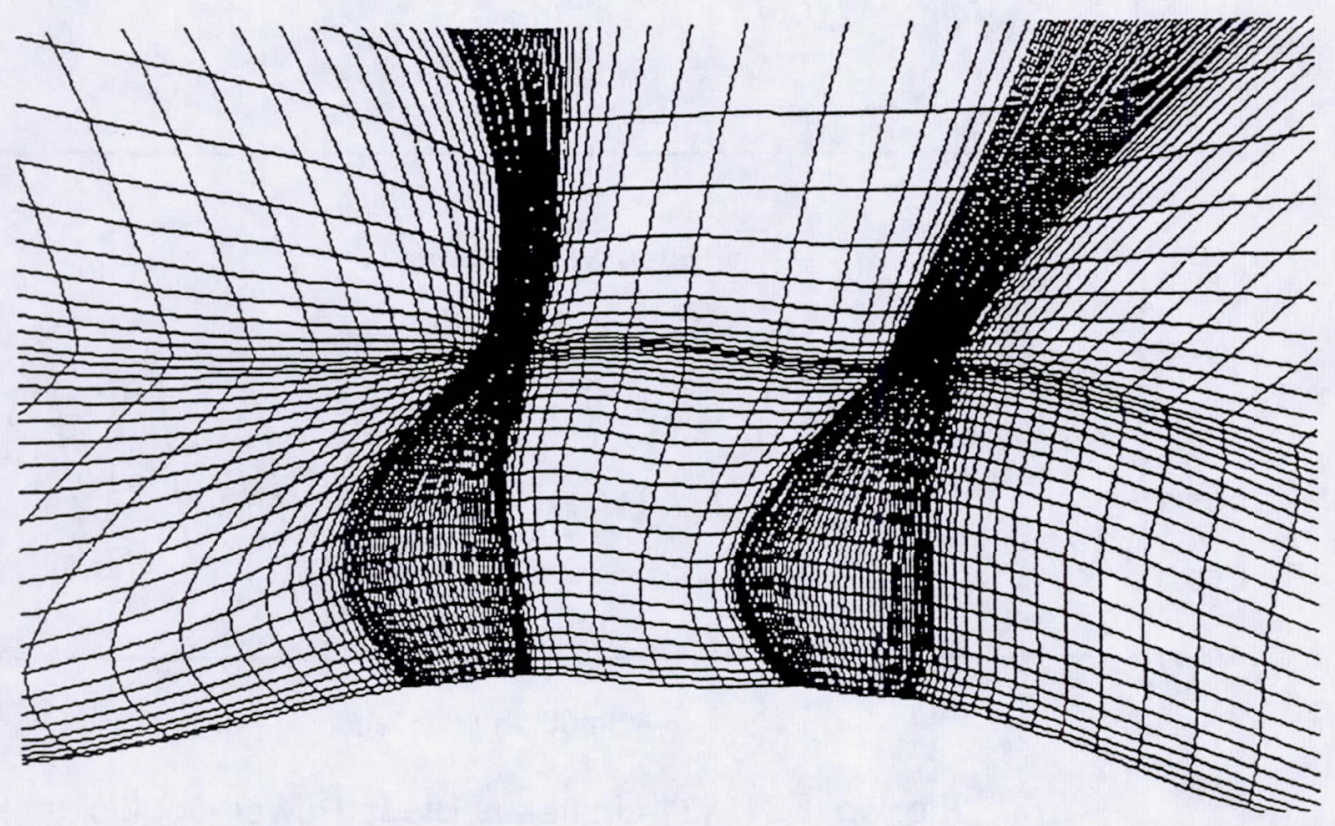

Fig. 4 Distribution of points on and near the F31/A31 blades 

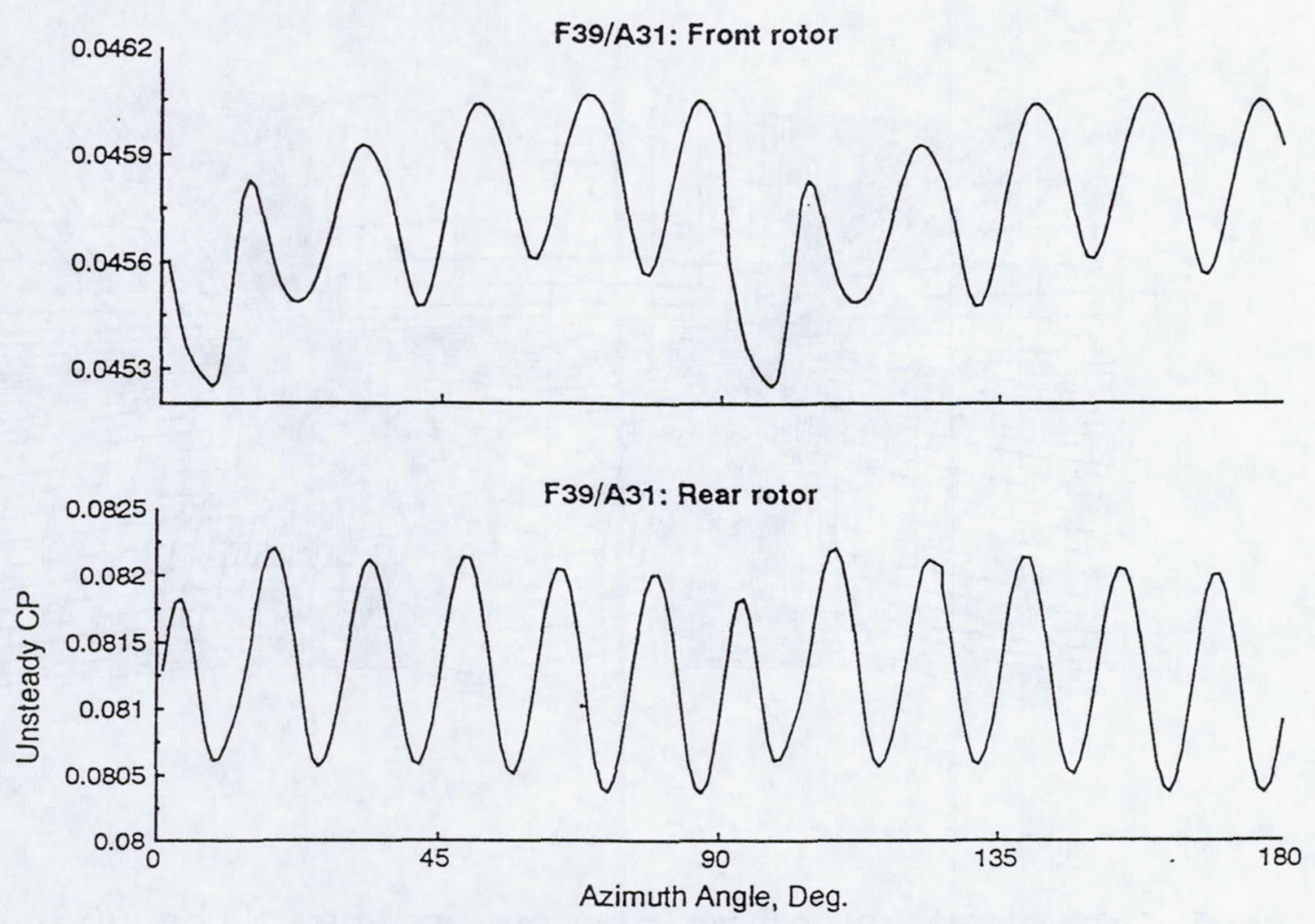

Fig. 5a F39/A31 Unsteady Blade Power Coefficient
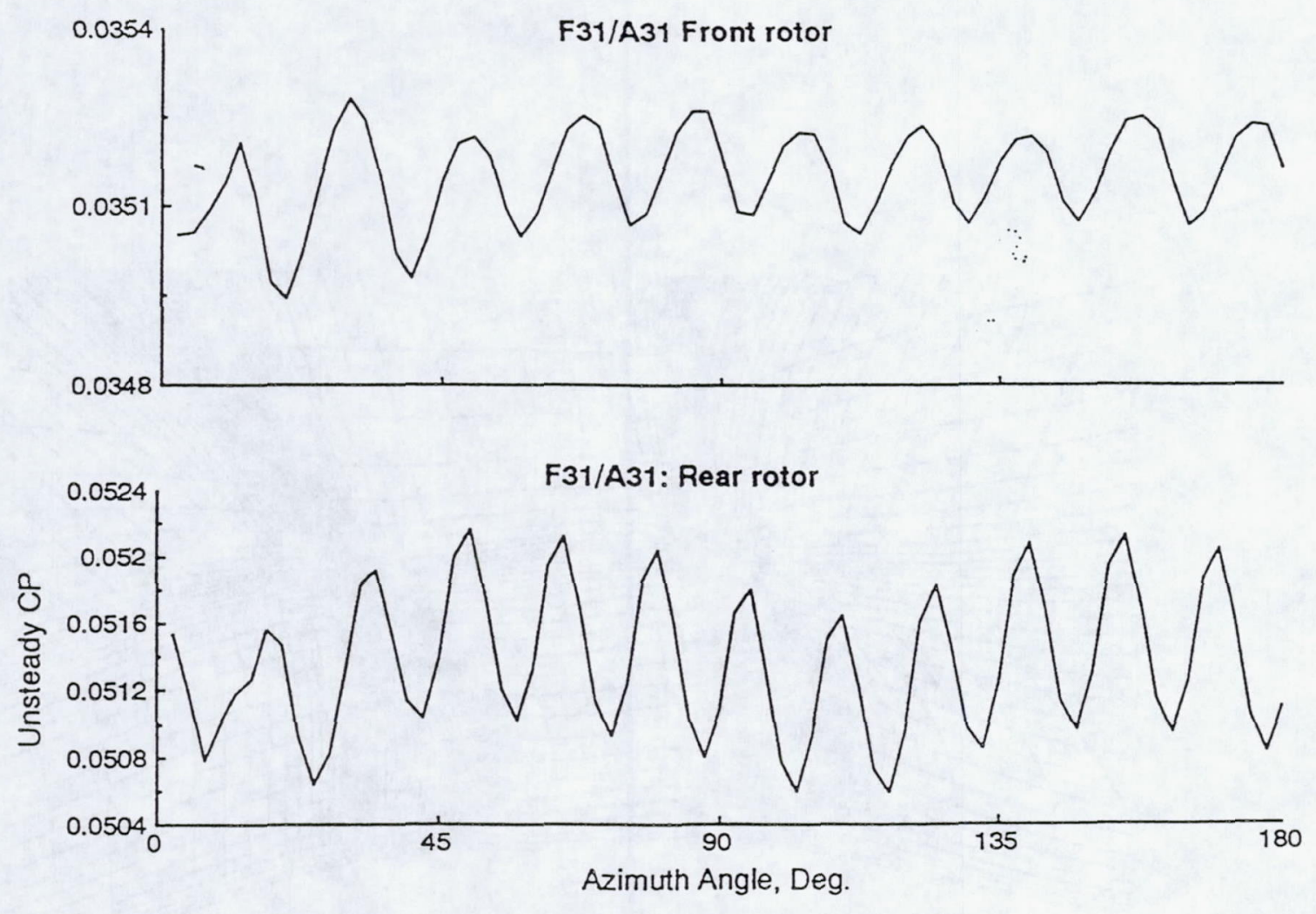

Fig. 5b F31/A31 Unsteady Blade Power Coefficient 


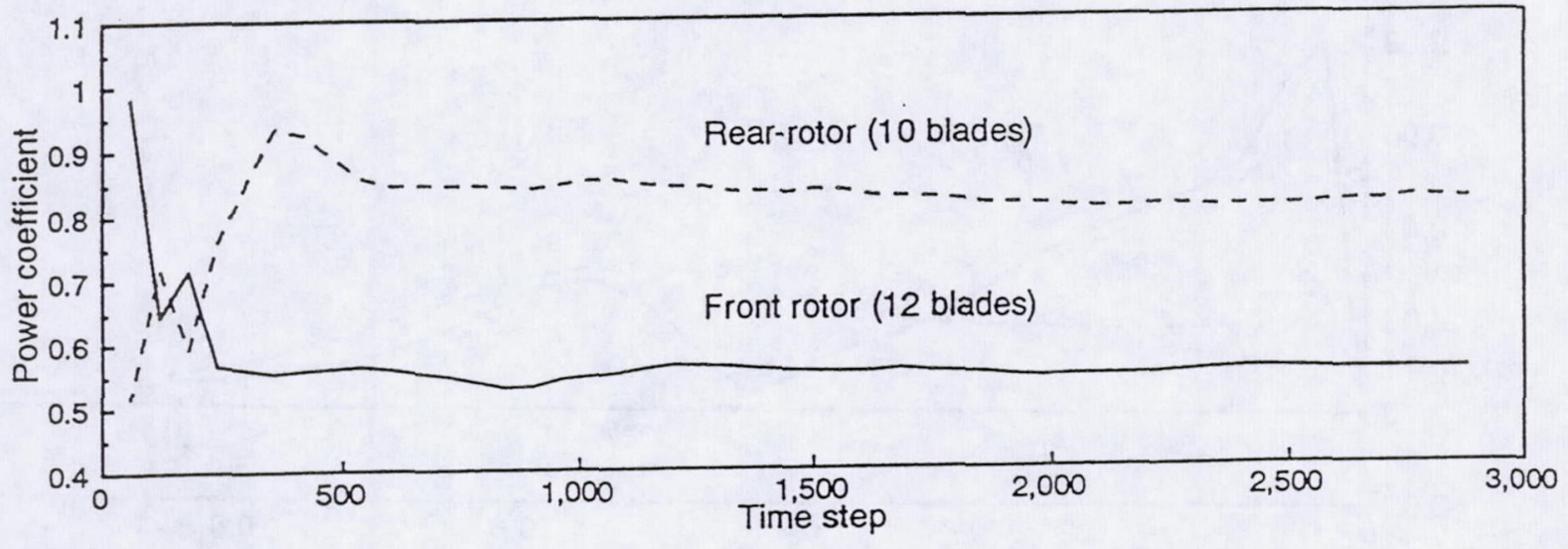

Fig. 6a Total power coefficient: F39/A31 (Forward-swept)

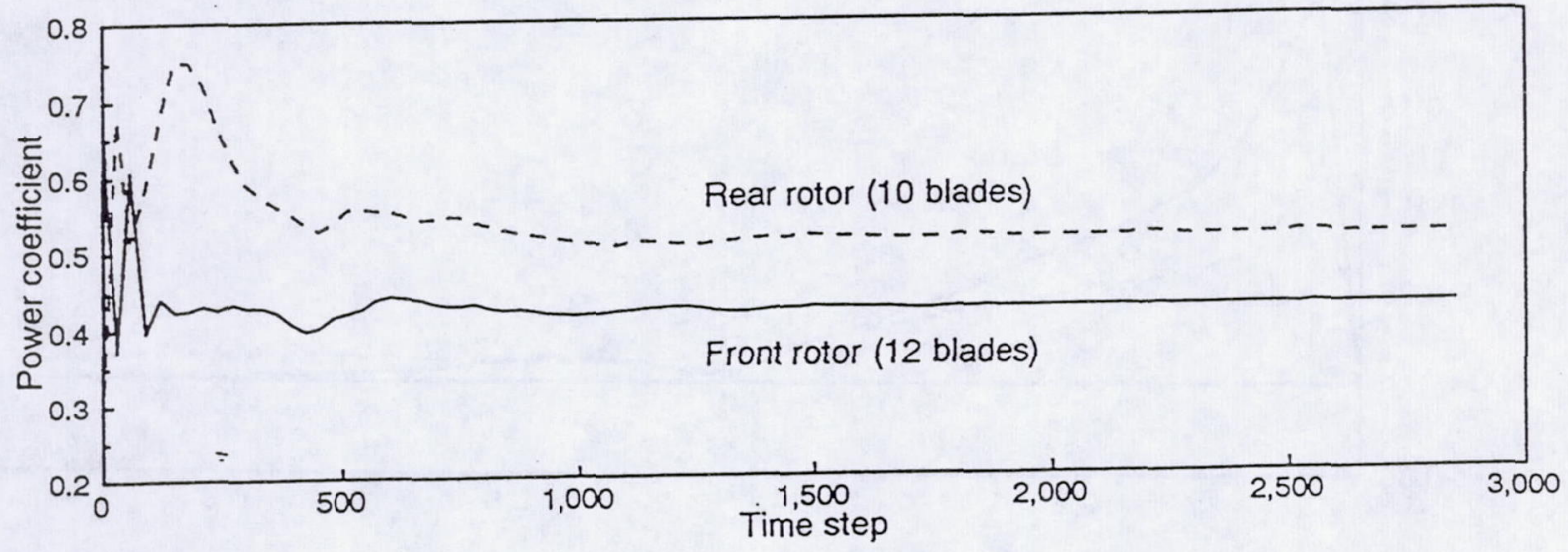

Fig. 6b Total power coefficient: F31/A31 (Aft-swept)

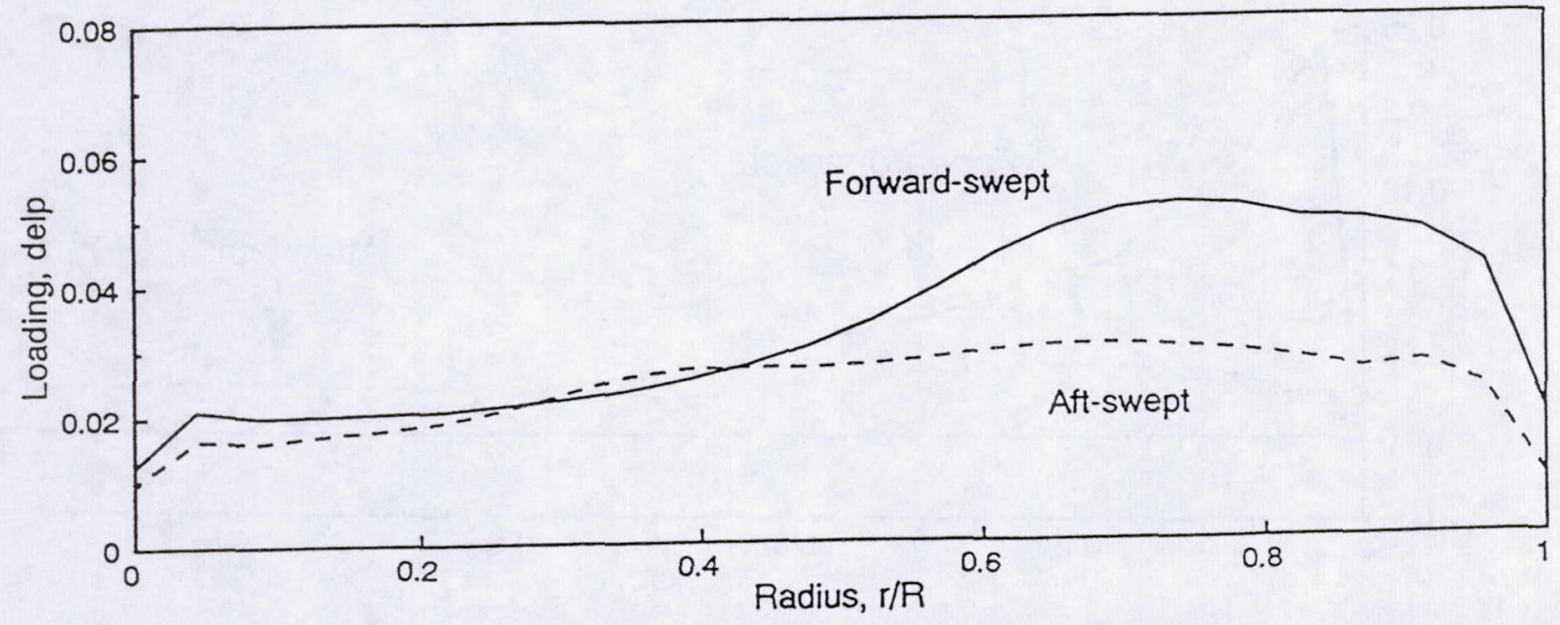

Fig. 7 Radial loading distribution 

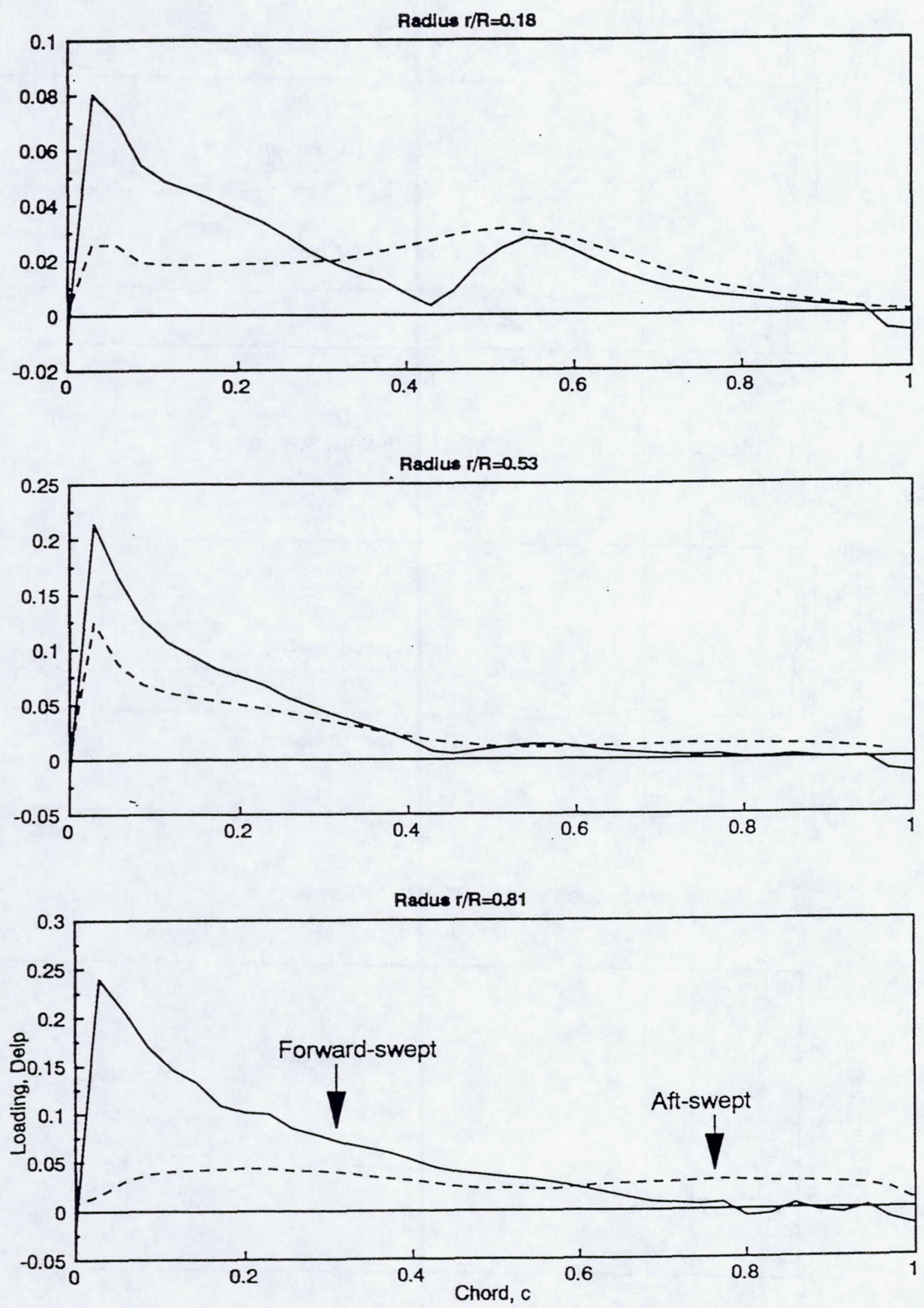

Fig. 8 Chordwise loading distributions of forward-swept and aft-swept blades 
Forward-swept

Suction surface Pressure surface
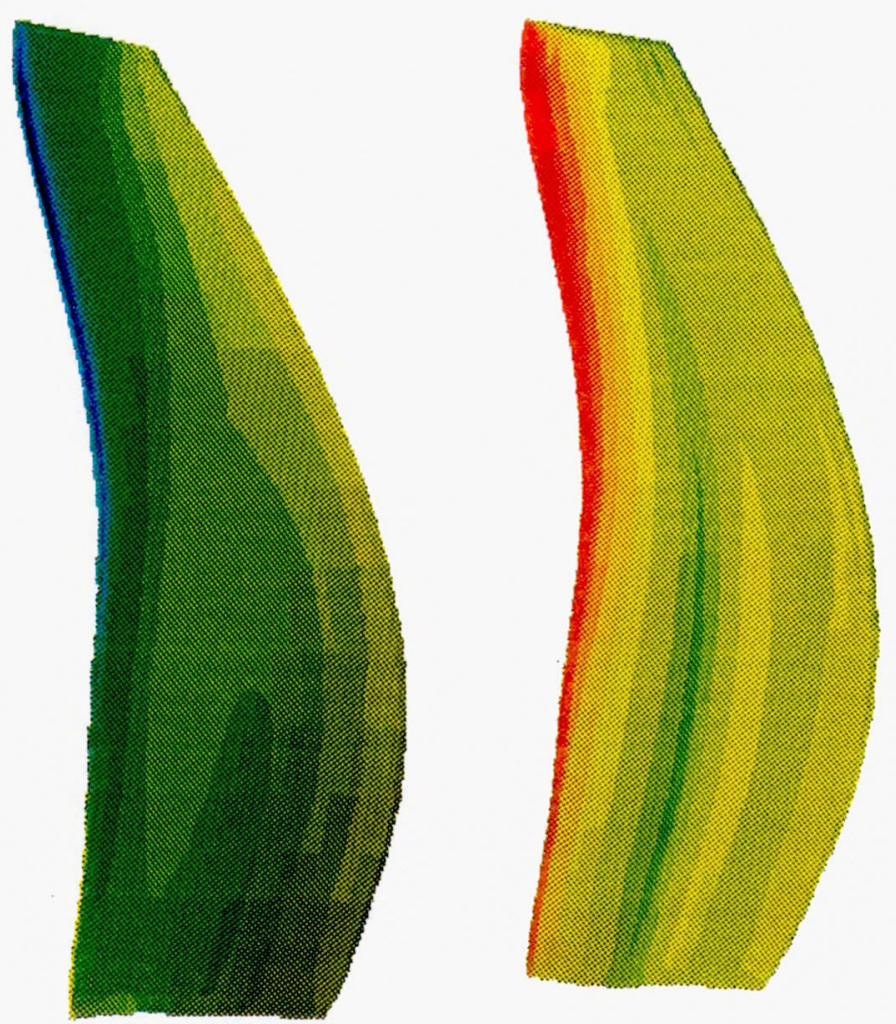

CONTOUR LEUELS

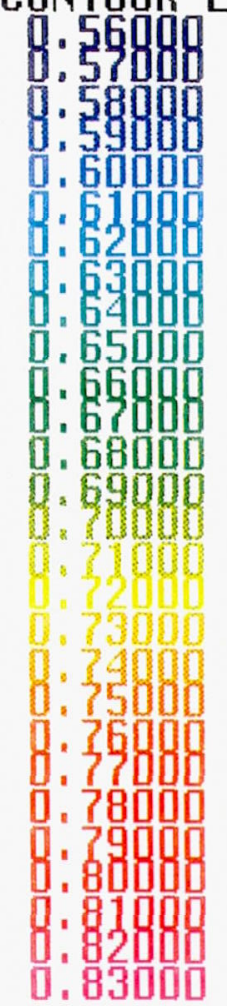

Aft-swept

Suction surface

Pressure surfssce

Fig. 9 Static pressure contours on the forward-swept and aft-swept blade surfaces 


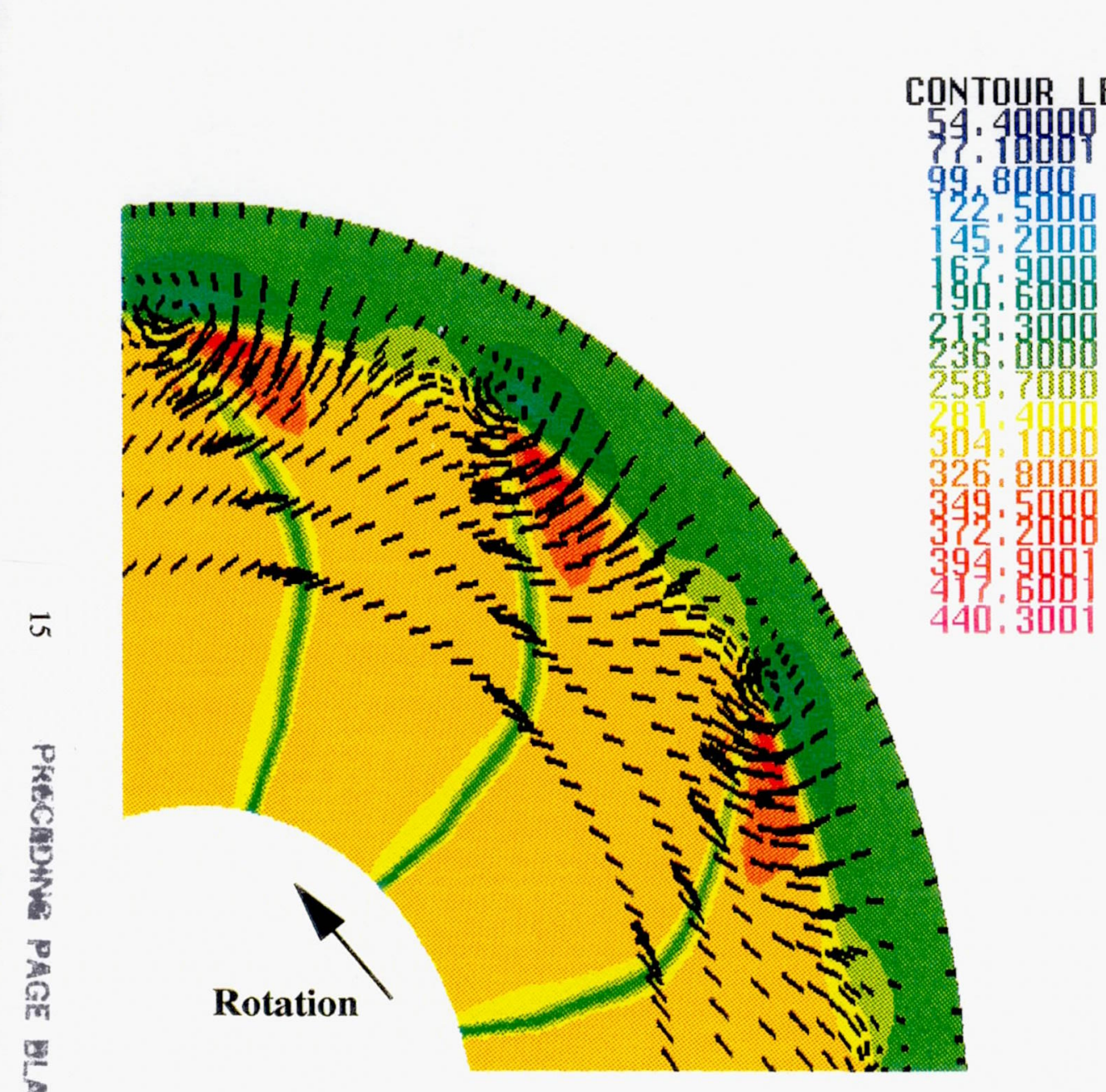

(a)
Crossflow vector reference $300 \mathrm{ft} / \mathrm{sec}$

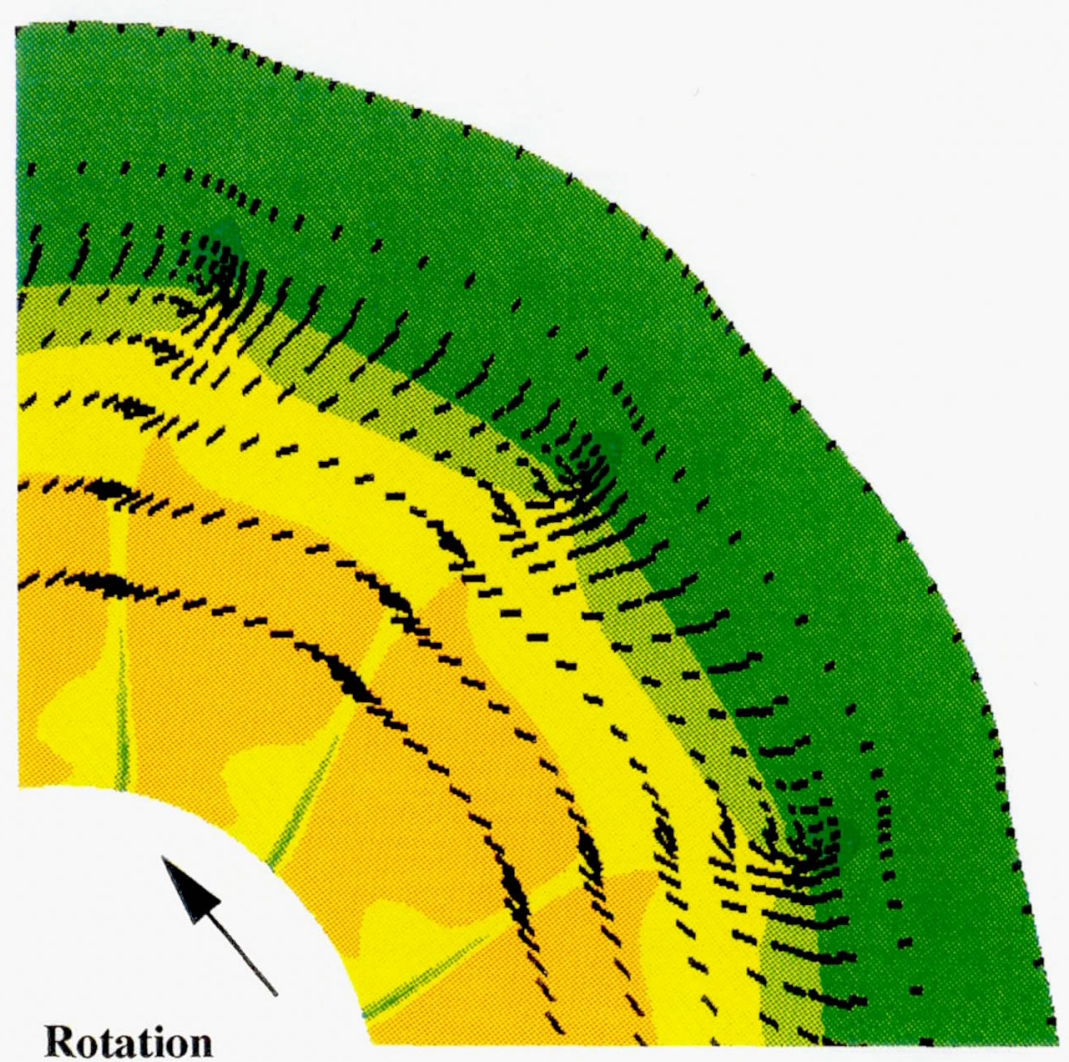

(b)

Fig. 10 Axial velocity contours and crossflow vectors downstream of trailing edge of (a) forward-swept blade (F39/A31) (b) aft-swept blade (F31/A31) 


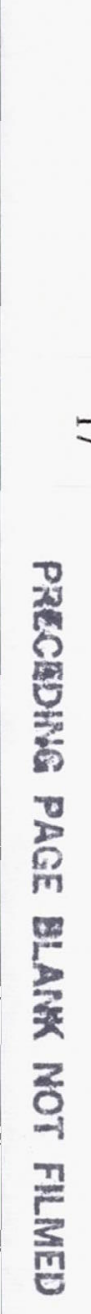

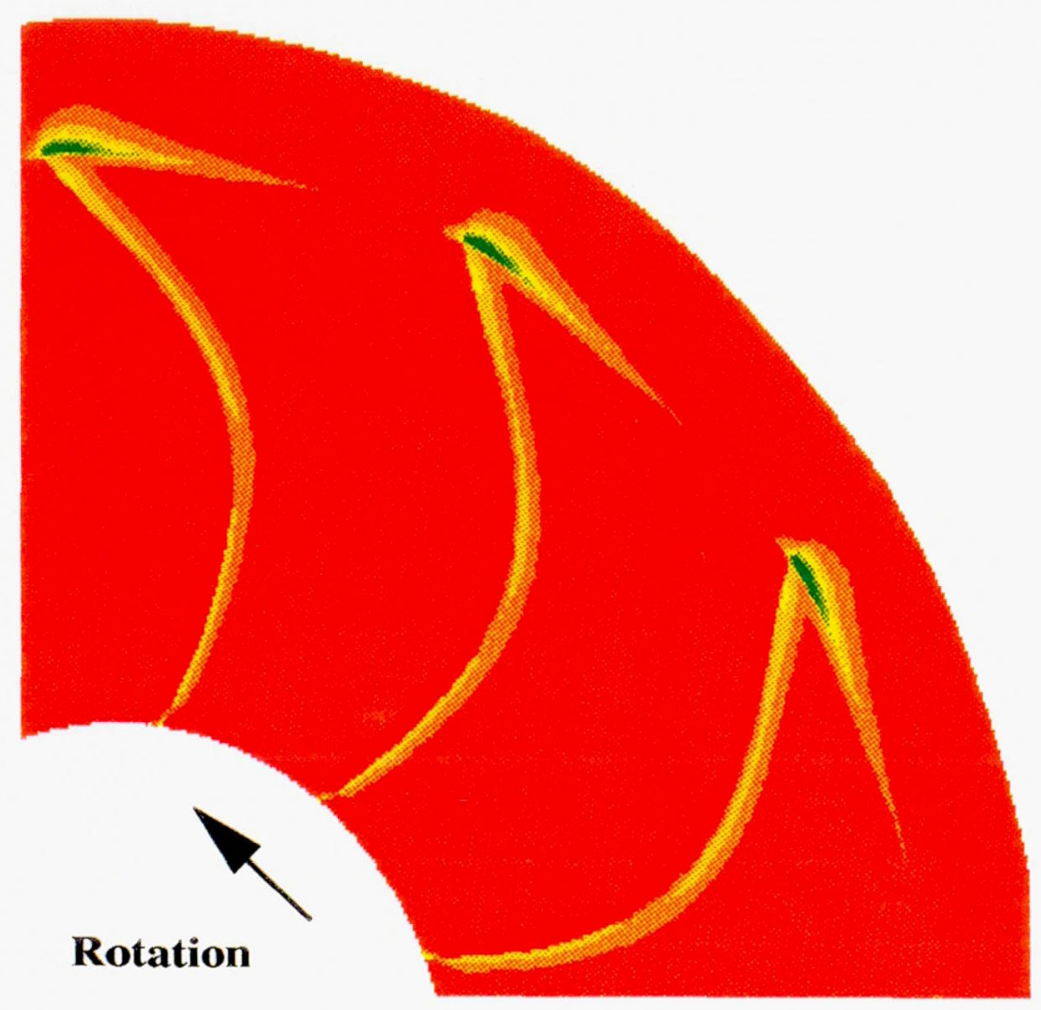

(a)

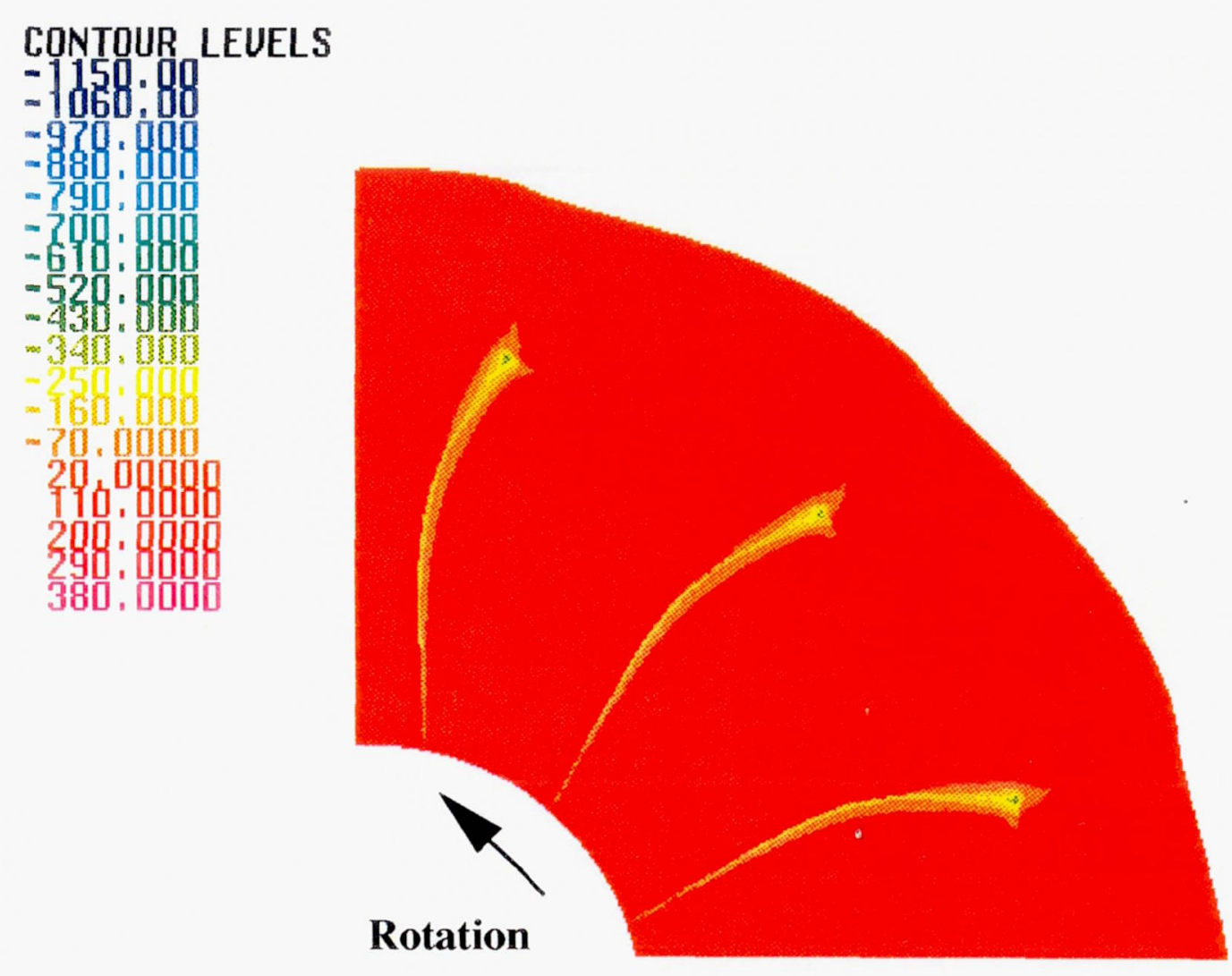

(b)

Fig. 11 Axial vorticity contours downstream of trailing edge of (a) foward-swept blade (F39/A31) (b) aft-swept blade (F31/A31) 

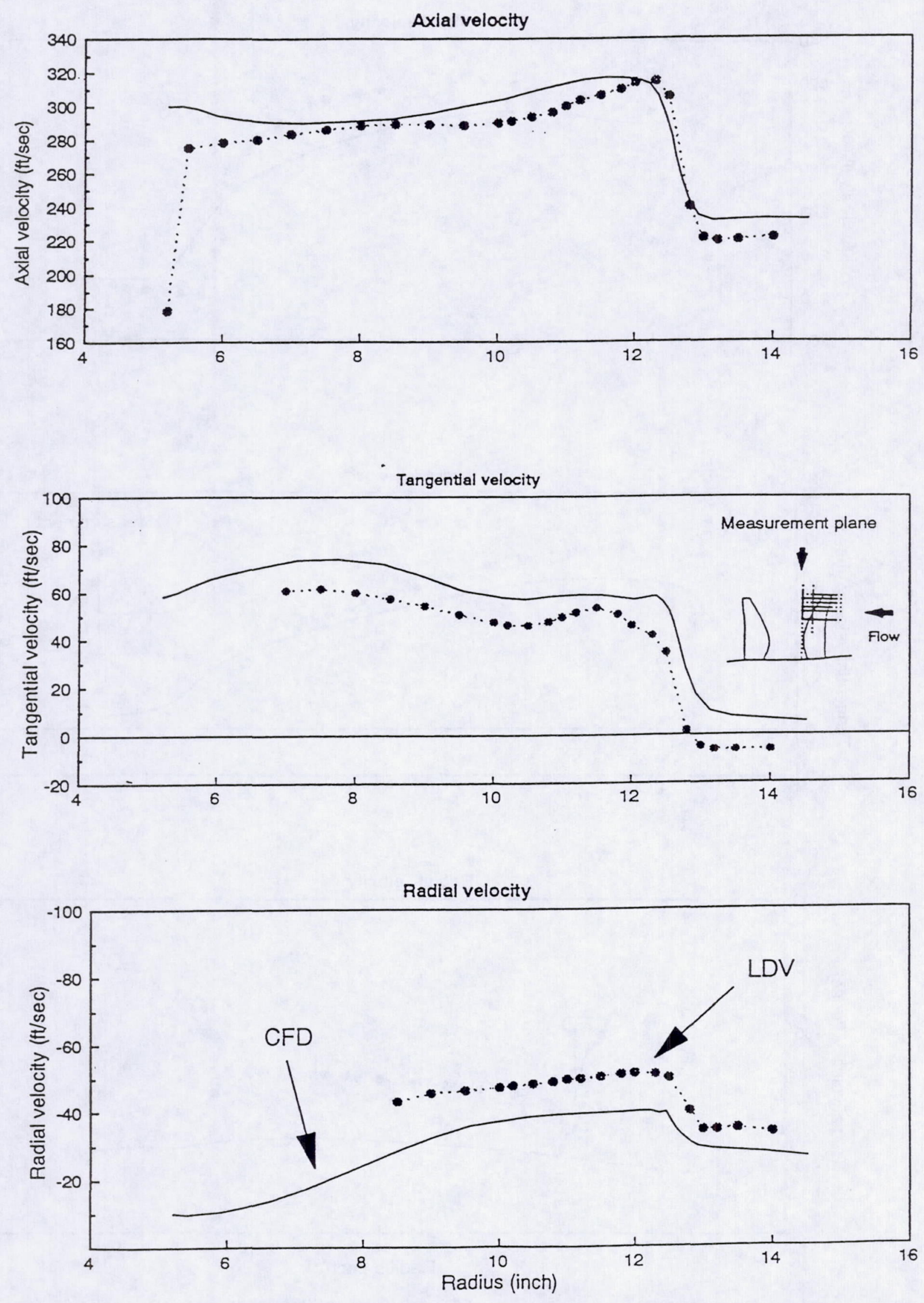

Fig. 12 LDV measured and Euler predicted velocities 1.79 in. downstream of forward-swept rotor 

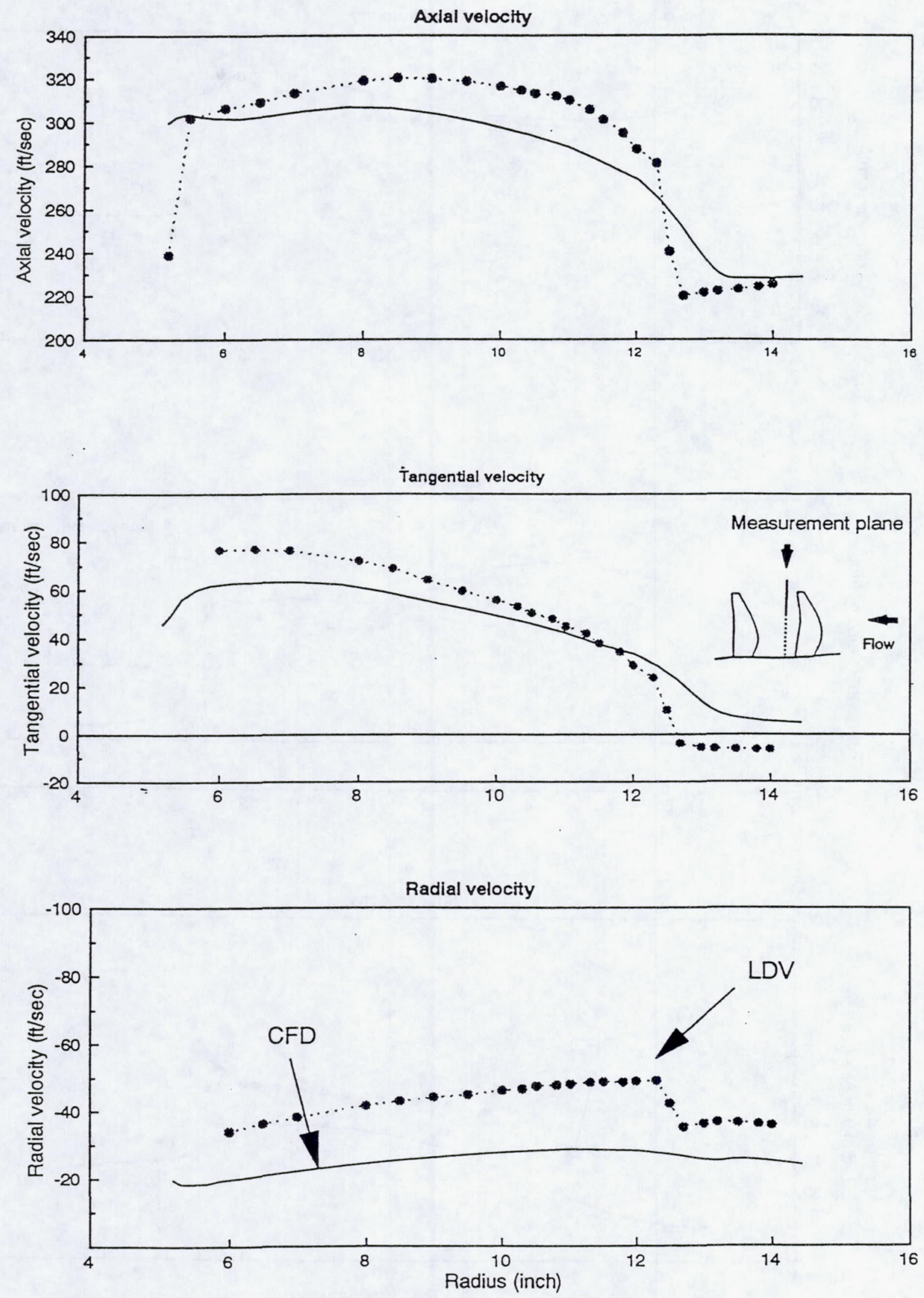

Fig. 13 LDV measured and Euler predicted velocities 2.42 in. downstream of aft-swept rotor 

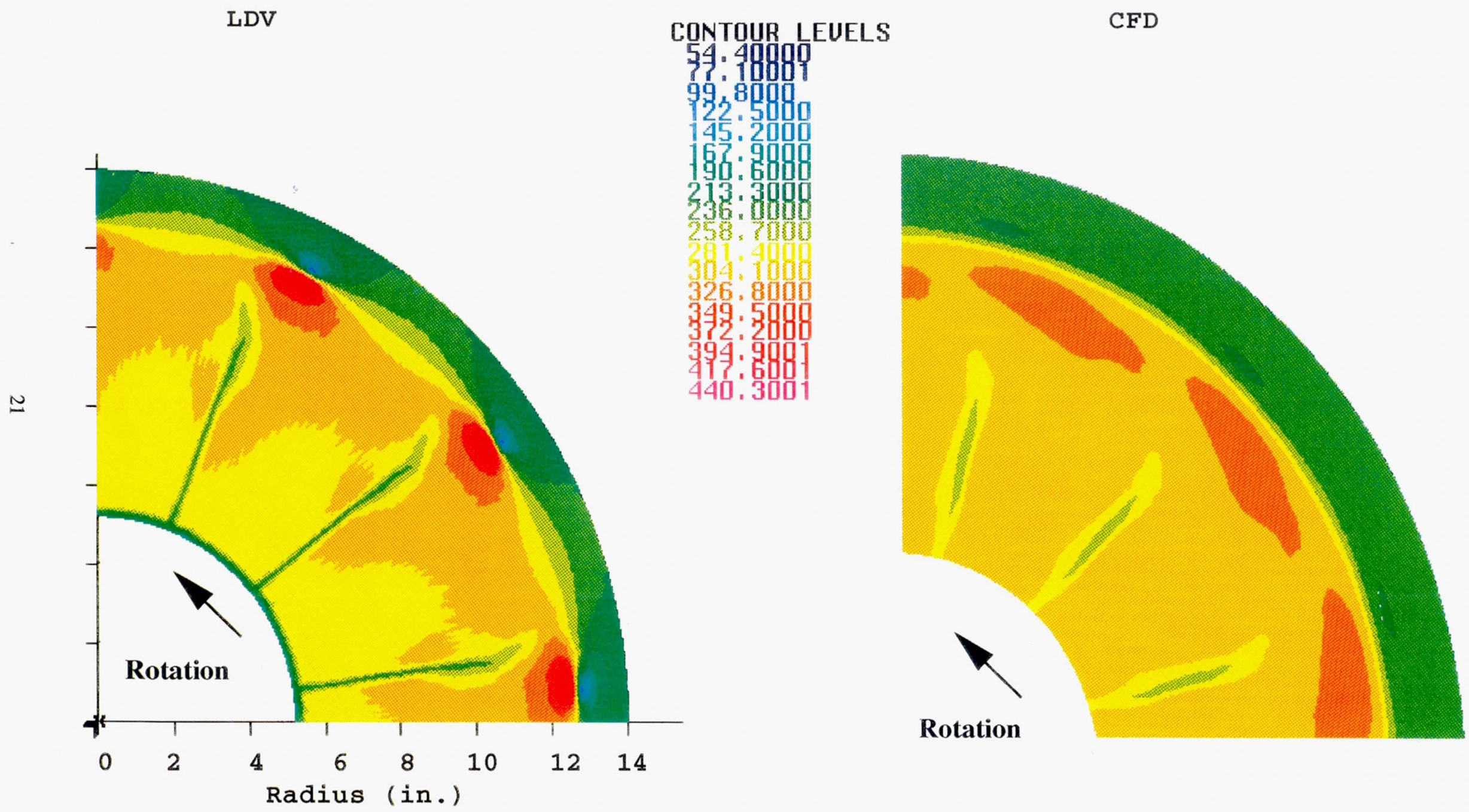

Fig. 14 LDV measured and Euler predicted axial velocity contours at 1.79 in. downstream of forward-swept rotor 


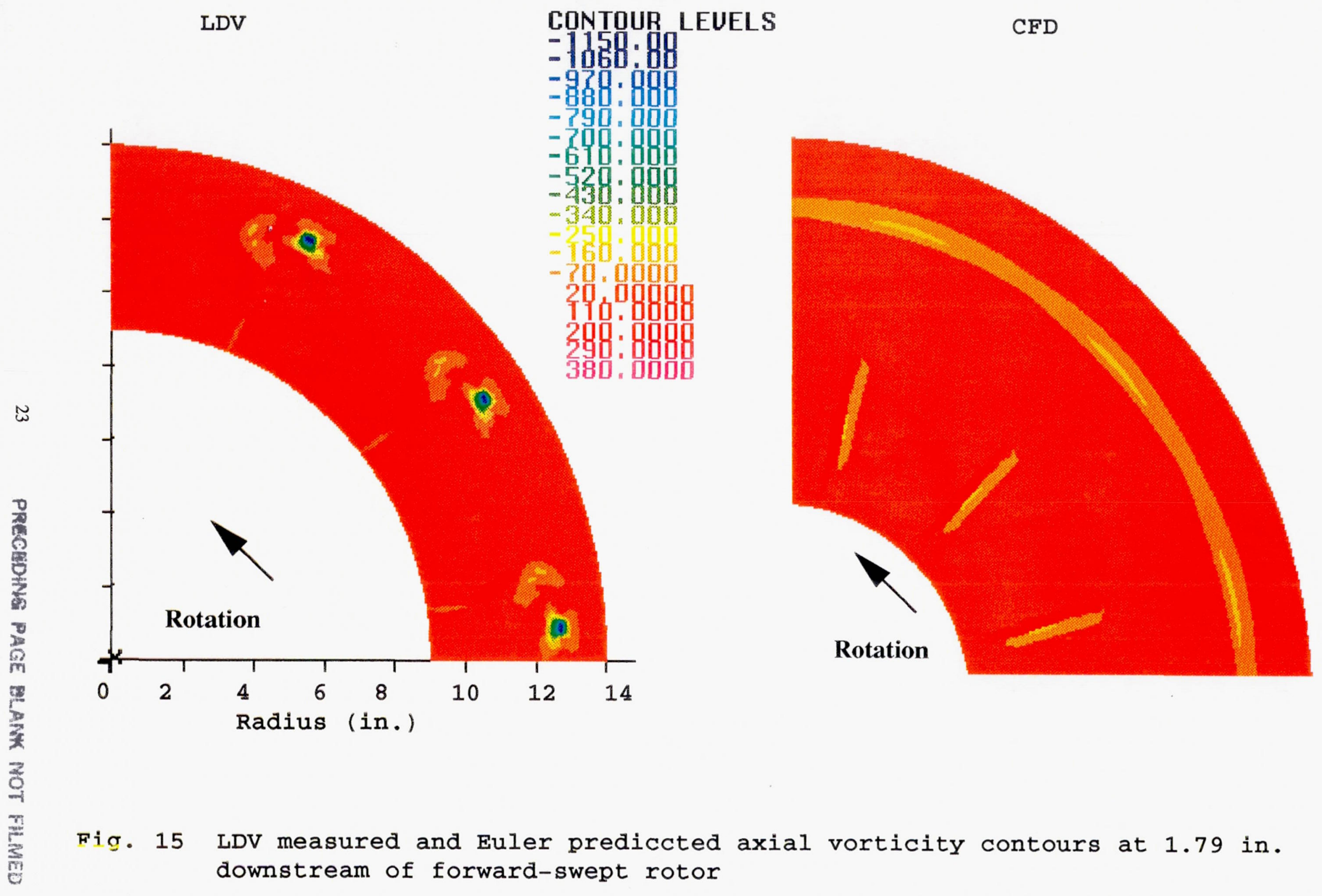


Public reporting burden for this collection of information is estimated to average 1 hour per response, including the time for reviewing instructions, searching existing data sources, gathering and maintaining the data needed, and cormpleting and reviewing the collection of information. Send comments regarding this burden estimate or any other aspect of this Davis Highway, Suite 1204, Arlington, VA 22202-4302, and to the Office of Management and Budget, Paperwork Reduction Project (0704-0188), Washington, DC 20503.

\begin{tabular}{|l|l|l|}
\hline 1. AGENCY USE ONLY (Leave blank) & $\begin{array}{c}\text { 2. REPORT DATE } \\
\text { August } 1994\end{array}$ & $\begin{array}{r}\text { 3. REPORT TYPE AND DATES COVERED } \\
\text { Technical Memorandum }\end{array}$
\end{tabular}

\section{TITLE AND SUBTITLE}

Effects of a Forward-Swept Front Rotor on the Flowfield of a Counterrotation Propeller

6. AUTHOR(S)

M. Nallasamy and Gary G. Podboy

7. PERFORMING ORGANIZATION NAME(S) AND ADDRESS(ES)

National Aeronautics and Space Administration

Lewis Research Center

Cleveland, Ohio 44135-3191

9. SPONSORING/MONITORING AGENCY NAME(S) AND ADDRESS(ES)

National Aeronautics and Space Administration

Washington, D.C. 20546-0001
5. FUNDING NUMBERS

WU-538-03-11
8. PERFORMING ORGANIZATION REPORT NUMBER

E-8994

\section{SUPPLEMENTARY NOTES}

Prepared for the 30th Joint Propulsion Conference cosponsored by the AIAA, ASME, SAE, and ASEE, Indianapolis, Indiana, June 27-29, 1994. M. Nallasamy, NYMA, Inc., Engineering Services Division, 2001 Aerospace Parkway, Brook Park, Ohio 44142 (work funded by NASA Contract NAS3-27186) and Gary G. Podboy, NASA Lewis Research Center. Responsible person, M. Nallasamy, organization code 2770, (216) $433-1287$.

12a. DISTRIBUTIONAVAILABILITY STATEMENT

12b. DISTRIBUTION CODE

Unclassified -Unlimited

Subject Categories 02 and 07

\section{ABSTRACT (Maximum 200 words)}

The effects of a forward-swept front rotor on the flowfield of a counterrotation model propeller at takeoff conditions at zero degree angle of attack are studied by solving the unsteady three-dimensional Euler equations. The configuration considered is an uneven blade count counterrotation model with twelve forward-swept blades on the fore rotor and ten aft-swept blades on the aft rotor. The flowfield is compared with that of a reference aft-swept counterrotation geometry and Laser Doppler Velocimeter (LDV) measurements. At the operating conditions considered, the forward-swept blade experiences a higher tip loading and produces a stronger tip vortex compared to the aft-swept blade, consistent with the LDV and acoustic measurements. Neither the solution nor the LDV data indicated the formation of a leading edge vortex. The predicted radial distribution of the circumferentially averaged axial velocity at the measurement station agreed very closely with LDV data, while crossflow velocities showed poor agreement. The discrepancy between prediction and LDV data of tangential and radial velocities is due in part to the insufficient mesh resolution in the region between the rotors and in the tip region to track the tip vortex. The vortex is diffused by the time it arrives at the measurement station. The uneven blade count configuration requires the solution to be carried out for six blade passages of the fore rotor and five passages of the aft rotor, thus making grid refinement prohibitive.

\begin{tabular}{|c|c|}
\hline $\begin{array}{l}\text { 14. SUBJECT TERMS } \\
\text { Counterrotation propeller }\end{array}$ & \\
\hline $\begin{array}{l}\text { 17. SECURTYY CLASSIFICATION } \\
\text { OF REPORT } \\
\text { Unclassified }\end{array}$ & $\begin{array}{l}\text { 18. SECURTYY CLASSIFICATION } \\
\text { OF THIS PAGE } \\
\text { Unclassified }\end{array}$ \\
\hline
\end{tabular}

\begin{tabular}{|c|c|}
\hline & $\begin{array}{c}\text { 15. NUMBER OF PAGES } \\
25\end{array}$ \\
\hline & $\begin{array}{r}\text { 16. PRICE CODE } \\
\mathrm{A} 03\end{array}$ \\
\hline $\begin{array}{l}\text { 19. SECURITY CLASSIFICATION } \\
\text { OF ABSTRACT } \\
\text { Unclassified }\end{array}$ & 20. LIMITATKN OF ABSTRACT \\
\hline
\end{tabular}

